\title{
Testing for the Disposition to Think Critically
}

\author{
STEPHEN P. NORRIS Memorial University of Newfoundland
}

Key Words: Critical thinking testing; critical thinking dispositions; test validity; dispositions.

\begin{abstract}
In order to test for critical thinking dispositions, the presence of the requisite critical thinking abilities must first be established. Otherwise, it is always a plausible counterexplanation of failure to use certain abilities that they were not possessed. If a person spontaneously uses some ability on a task, then it is often legitimate to conclude that the person has both the ability and the disposition to use it. However, if the person does not use the ability spontaneously, the conclusion is ambiguous. The person might not have the ability, or might have the ability but not the disposition to use it, or not the disposition to use it in the specific circumstances of the presented task. This paper proposes methods of critical thinking testing designed to deal with each of these possibilities.
\end{abstract}

Fisher (1991) has offered a very useful critique of Paul's, Glaser's, and Bowen's proposed Fairmindedness Subtest for the Watson-Glaser Critical Thinking Appraisal (Watson \& Glaser, 1980) -one of the few attempts to construct a test of a critical thinking deposition. While some progress has been made in testing for critical thinking abilities, the ground has hardly been broken in testing for critical thinking dispositions, so work in this area is very important. In this paper I explore a bit further than Fisher how testing for critical thinking dispositions might be approached and offer some additional suggestions for improving the Fairmindedness Subtest.

The first part of the paper focuses on the distinction between dispositions and abilities. The second section addresses the logic of testing for dispositions. The third section gives an example of a test format that might be useful for testing for various dispositions to think critically. Finally, further suggestions for improving the Fairmindedness Subtest are offered. ${ }^{1}$

\section{The Distinction between Dispositions and Abilities}

Let us examine first the distinction between abilities and dispositions in the case of inanimate objects. We might say the following about aluminum, for example: "Aluminum has the ability to conduct electricity". By such a statement we would mean that aluminum is a material such that, when there is a net potential difference (voltage) applied across it, then it will conduct electricity. That is, to say that aluminum has the ability to conduct electricity is to say what aluminum will do because of its nature when put into certain circumstances (Harré, 1970, Ch. 10).

In such a situation, there seems to be little need to differentiate between abilities and dispositions. The statements, "Aluminum is electrically conductive" and "Aluminum is disposed to conduct electricity", mean the same thing as the previous statement about aluminum's ability to conduct electricity. They mean the same because aluminum does not have the choice of whether or not to conduct electricity. If the conditions are right, the laws of nature demand that aluminum conduct electricity. That is, for inanimate objects, to say that they have dispositions to behave in certain ways is (at least often) just another way of saying what abilities they have.2

Such is not the case with human beings. To say that a person has an ability to do such-and-such is to say that, under 
certain conditions, the person will do such-and-such, only if so disposed. The disposition condition is required for human beings, because they must either have formed habits to use certain abilities, or overtly think to use the abilities they possess, and, having formed habits or thought to use them, choose whether or not to do so. In order to deal with the different senses in which human beings and inanimate objects possess abilities and dispositions, I propose distinguishing between a probability and a free will sense of disposition, and between spontaneous abilities and stimulated abilities.

\section{Probability and Free Will Senses of Disposition}

A person is disposed in the probability sense to use ability such-and-such in appropriate circumstances when the person habitually uses or thinks to use the ability. A person who thinks to use an ability and, in addition, chooses to use it in appropriate circumstances is disposed in the free will sense.

These senses of disposition to use an ability require different instructional approaches for their promotion. For instance, instructing students so that they acquire the disposition to think critically in the probability sense implies the need for considerable practice with thinking critically in a variety of contexts. Instructing students so that they acquire the disposition to think critically in the free will sense involves more than practice. The issue is a motivational one, and, in part, an ethical one: students have to be taught why thinking critically makes sense and why it is often the only ethical way to acquire beliefs. They must learn that, since action is based on belief, and since action always has an ethical dimension, then belief acquisition has an ethical dimension. They also must learn that it is only through thinking critically that knowledge can be acquired. These are lessons taught not by practice, but by argument, explanation, and example.

\section{Spontaneous and Stimulated Abilities}

"Spontaneous ability" refers to what a person is able to do, and disposed to do; it is an ability coupled with a disposition in both of the above senses. "Stimulated ability" refers to what a person is able to do, but disposed to do only when prompted.

Spontaneous abilities in humans are like the abilities of inanimate objects. Thus, to say that Jane has the spontaneous ability to judge alternative explanations of events is to say that Jane is such a person that, when a situation calls for judging alternative explanations, she judges them without further motivation. She either habitually uses the ability she has, or she thinks to use the ability, and then she chooses to use it.

However, there is Shirley who has the ability to judge alternative explanations of events but she must be reminded that various explanations are under consideration; she must be prompted to think of criteria that can be used to judge explanations; she must be urged to weigh and balance the pros and cons of each; and so on. Shirley has the ability to judge alternative explanations of events, because she can recognize something as an explanation when reminded to look for explanations, and knows the criteria for judging explanations and how to use them. However, she does not think spontaneously to use the ability she possesses or, if she thinks to use it, does not choose to do so. Shirley has a stimulated ability to judge alternative explanations of events. A notion from cognitive psychology, inert knowledge (Bereiter \& Scardamalia, 1985), that is, knowledge that people have but do not think to use, is another way to characterize this aspect of Shirley's critical thinking ability.

Evidence of individuals possessing abilities in the two senses is found in various studies. In his research on everyday reasoning, Perkins (1983) identified individuals who do not use fully the abilities they have. For example, in dealing with 
problems that are best solved by considering several factors on each of several sides of an issue, Perkins' studies show people who tend to propose and to consider very few factors on only one or two sides. Thus, their spontaneous ability to propose and to consider alternatives is low. However, these same people appear to possess the stimulated ability at least to propose alternatives, because, when given such directives as proposing four factors on each of three sides of an issue, they follow the directives, or follow them reasonably well.

Research in the area of reading comprehension by Markman (1979) shows that children often do not recognize spontaneously inconsistencies in textual material, even though they can recognize inconsistencies under certain types of questioning from a teacher or researcher. Research by Sheppard (1991) shows that grade six students are much better observers in science activities when they are asked leading questions about what they should do. Sheppard argued that the students have more knowledge and ability to observe than they use spontaneously, but that they do not search well on their own for information relevant to the tasks under consideration.

Norris and Hollett (1992, July) were able almost to double high school students' scores on the Ennis-Weir Critical Thinking Essay Test (Ennis \& Weir, 1985) by providing some simple hints about what they might consider in responding to the letter in the test. The hints (e.g., "think about the meaning of the words used") were designed to be helpful only to students who knew how to think critically about certain issues, and to be unhelpful to students who lacked critical thinking ability. The doubling of scores of the experimental group over a control group was taken as evidence that the students had critical thinking ability that they did not use spontaneously.

Thus, to say someone has the ability to do such-and-such is ambiguous between saying that they have the spontaneous ability or the stimulated ability. When a person has a spontaneous ability, the disposition to use, or to think and to choose to use, the ability in appropriate situations is integrated with the ability itself. When a person possesses a stimulated ability, then the disposition (in either one or both of its senses) to use the ability is lacking.

The distinction is important for education. Most educational goals are directed toward producing people with spontaneous abilities, that is, abilities integrated with the disposition to use them in appropriate situations. Also, for instructional purposes, it is important to distinguish those students who possess a stimulated ability from those who possess no ability at all, because the two groups need quite different forms of instruction. Also, further research might show that particular abilities are spontaneous in some contexts but require stimulation in others and, depending upon practice and other factors, that spontaneous abilities revert to stimulated ones or that stimulated abilities change into spontaneous ones. All such findings would have implications for instruction. However, before we can evaluate the effectiveness of instruction or explore the development of dispositions, we need instruments that can test validly for critical thinking dispositions. Before we can design such instruments, we need to understand what they need to show and how they must work. I turn now to these issues.

\section{The Logic of Testing for Dispositions}

Testing for the disposition to use critical thinking abilities requires logically two steps. In the first step, examinees must be presented with a task on which using the critical thinking abilities of interest reasonably can be expected. Meeting this condition is necessary, because, if there is no good reason to expect those abilities to be used, then one cannot 
conclude when examinees fail to use the abilities that they do not have a disposition to think critically where appropriate. Fisher (1991) has shown, for instance, that parts of the Fairmindedness Subtest ask examinees to make choices that may not be reasonable in the context to expect them to make.

The task must be presented so that nothing leads examinees to use the abilities in question. Otherwise, conclusions about stimulated abilities and not about dispositions are the only ones that could be drawn from examinees' performance. If, when presented a task meeting these two requirements, examinees use spontaneously the abilities in question, then this is evidence that they have the disposition (in both probability and free will senses) to use those abilities.

If examinees fail to use the abilities being tested, then the fact that this failure can be explained in several possible ways presents a serious threat to the validity of disposition tests. One possible explanation is that examinees possess the abilities only in the stimulated sense, that is, they have the abilities but not the disposition in the probability sense to use them or to think to use them. A second explanation is that they do not possess the abilities in either the spontaneous or stimulated sense. A third explanation of examinees' failure to use the abilities being tested is that they possess both the abilities and the disposition (in the probability sense) to use them, but, for one reason or another, just choose not to. They do not have the disposition in the free will sense.

The logic of the testing situation requires that these three competing explanations be adjudicated in another set of testing tasks-the second step needed for disposition testing. I cannot here offer tried and proven methods for achieving the necessary adjudication, but I will use an example to suggest a potentially fruitful approach.

\section{An Example Critical Thinking Disposition Test}

Consider the Essay Test of Inductive Reasoning Strategies (Norris \& Ryan, 1987). The test presents examinees with a fictional situation. They must imagine that they are on the planet Zed searching for living creatures. They are then presented a day-by-day account of things that happen during their stay and, while keeping in mind their search for living creatures, they are to write what they are thinking and what they plan to do because of the things that happen. A portion of the test follows:

\section{Are There Living Creatures on Zed?}

\section{Directions}

This test asks you to write down what you are thinking and what you plan to do as you work on a problem.

You and two scientists must search the planet Zed for living creatures. You have only four days to explore before returning to Earth. Some of the things that happen each day are described.

Read about the things that happen on each day, and think about what they mean for your search for living creatures.

Then, keeping in mind your search for living creatures:

(1) write what you are thinking about the things that happened on that day and previous days; and

(2) write what you plan to do on your search because those things happened.

Day 1

Your spaceship lands where you think your search might be successful. With life support suits on, you and the scientists start to walk away from the ship. You hear some high-pitched sounds which last for about twenty or thirty seconds. Then, your radio buzzes a warning. You return to the spaceship to check the instruments. You find a tape recorder is on. When the scientists re turn to the ship, neither remembers having turned on the recorder. 
Now, write what you are thinking and what you plan to do.

\section{DO NOT GO AHEAD UNTIL FINISHED DAY 1}

\section{Day 2}

Today, you set out for a nearby hill. When you reach the top you see a valley below. There is a river flowing through the valley with a variety of vegetation and rock formations on either bank. You take some photographs of the landscape and begin to follow the river downstream. The water here is very clear and you can easily see to the bottom. In the water there are several cone-shaped, brownish objects which look like broken pieces of large eggshells. You pick one from the water. It is thin and you are able to crack it easily like an eggshell. You take it back to the ship.

Now, write what you are thinking and what you plan to do.

The test is designed to assess the ability and disposition to use several strategies of good inductive reasoning. The strategies include: keeping the main point in mind; taking all information into account; seeking more information when necessary; considering alternative interpretations, plans, conclusions, and hypotheses; and withholding judgement where appropriate.

Let us examine the test with respect to the logic of testing for dispositions. For simplicity, let us focus on only one strategy: considering alternative interpretations, plans, conclusions, and hypotheses. The first requirement is that the test present a task on which it is reasonable to expect the use of this strategy. Is this the case? If Day 1 is examined, a number of relevant occurrences are noticed: some high-pitched sounds are heard, a warning is buzzed, and a tape recorder is discovered to be on. These occurrences are relevant to the task of searching for living creatures, because any or all of them could be explained by the existence of such creatures on Zed. So it is reasonable to expect examinees to indicate that they believe these events to be relevant. However, it is clear that the existence of living creatures is not the only, probably not even the most plausible, explanation of the events. The warning, for example, could have been caused by some instrument malfunction or by the recorder being on. The recorder could have malfunctioned, or it could have been left on by one of the scientists, even though they do not remember doing so. Since these alternative interpretations and hypotheses are plausible, and since thinking about whether there are living creatures on Zed should be tempered by consideration of such alternatives, then it is reasonable to expect examinees to mention them, or ones like them. Thus, the first requirement for testing for the disposition appears to be satisfied.

The second requirement is that examinees not be led to consider alternative interpretations, plans, conclusions, and hypotheses by something in the testing situation. The initial instructions are designed to be nonleading. Examinees are asked merely to write what they are thinking and what they plan to do on their search because certain things happened. There is nothing in these instructions to suggest to examinees that they should consider alternatives.

Since both requirements are met for the first testing step, examinees who consider alternative explanations of the events occurring each day provide evidence that they have the spontaneous ability to do so, and thus are disposed (in both senses) to do so.

If examinees fail to consider alternative interpretations of the occurrences, then there at least three possible conclusions: (a) the examinees have the ability to consider alternatives only in the stimulated sense; (b) the examinees do not have the ability to consider alternatives in either the spontaneous or the stimulated senses; or (c) they have the ability and the disposition (in the probability sense) but, do not have the disposition in the free will sense. To choose among these interpretations the second step in testing is undertaken. 
The method for proceeding with the second step to be proposed here is that the examinees involved be interviewed individually. Suppose we consider Day 2, during which are found "several cone-shaped, brownish objects which look like broken pieces of large eggshells." Consider the undergraduate university student who wrote the following in response to this day's events:

The eggshell indicates that something had hatched in the water. There must be some kind of creature. Further analysis of the shell may help.

This student appears to have taken the eggshell-like objects to be eggshells. Does this indicate an inability to distinguish between something that might be an eggshell and something that is? Does it indicate an inability in this case of imagining what else an eggshell-like object might be other than an eggshell? Does it indicate a disposition to jump to conclusions rather than to consider alternatives?

One way of gaining further information to help answer these questions is to conduct an individual interview with the student (Norris \& Ennis, 1989). This extends Fisher's (1991) suggestion, to use interviews with examinees in constructing a test, to the use of interviews in the actual testing situation. Questions to examinees should be at first as nonleading as possible (Norris, 1990, 1992). An initial question to the examinee might be as follows: "Would you read about Day 2 once more, read what you have written, and tell me whether there is anything else that comes to your mind?" The examinee's answer to this probe may be sufficient to indicate that what the examinee wrote does not provide an accurate indication of his or her ability or disposition. For example, the examinee may suggest that the eggshell-like object is worth further exploration because it could possibly be from some kind of living creature, but that judgement should be withheld because it might also be some sort of rock formation or hardened bubbles of lava. Such a response would be evidence that the examinee has the stimulated ability to consider alternative interpretations, but not the disposition in the probability sense. It seems the student has the disposition in the free will sense, because in response to the moderate stimulation that led the student to think of alternatives, the student offered an analysis of some of the alternative explanations possible in this situation.

In response to the probe, on the other hand, the examinee may give basically the same response as he or she gave in writing. At this point, some form of more leading questions might be asked. First, it is not clear that the student has recognized that the text does not say the object is an eggshell. You might start by asking, "Why do you think the object is an eggshell?" This probe has several possible outcomes, one of which might be the immediate recognition by the examinee of a failure to read carefully. Another possibility is that the examinee might have recognized the circumspect description but simply could not imagine that an eggshell-like object on Zed could be anything other than an eggshell. This latter finding might indicate a context-specific lack of ability on the part of the examinee, indicating that it would make sense to test the person in other contexts to see whether he or she had the ability and disposition to consider alternatives in those situations.

Another result of asking to explain why the object is an eggshell is that the examinee recognizes that he or she should have been more tentative, but still does not suggest alternative interpretations for consideration until asked explicitly in a subsequent question. Such a person would seem to have the stimulated ability to consider alternatives but not the disposition (probability sense) to do so. However, the person seems to have even less disposition than the student who responded fully after one nonleading question. The instruction suggested by this diagnosis might consist in 
trying to show the person how the consideration of alternatives can lead to more focused and efficient thinking and in providing considerable practice thinking in situations in which considering alternatives is appropriate. There would also be benefit in attempting to explore what it was about the situation that hindered the student from thinking to use an ability that he or she possesses.

\section{The Fairmindedness Subtest}

Paul's, Glaser's, and Bowen's Fairmindedness Subtest needs reconsideration as a model for disposition testing, because, in addition to the reasons offered by Fisher, it fails to satisfy the logical requirements of disposition testing. To test for critical thinking dispositions, the presence of the requisite critical thinking abilities must first be established. Otherwise, it is always a plausible counterexplanation of failure to use certain abilities that they were not possessed. The explanation that they were possessed and examinees were not disposed to use them faces this competitor unless a second stage of testing rules it out by gathering additional information. The Fairmindedness Test does not follow this two-step procedure.

\section{Concluding Remarks}

If a person spontaneously uses some ability on a task, then it is often legitimate to conclude that the person has both the ability and the disposition to use it. This is the easiest case in testing for critical thinking dispositions. However, if a person does not use spontaneously an ability, the conclusion is ambiguous. The person might not have the ability, or might have the ability but not the disposition to use it, or not the disposition to use it in the specific circumstances of the presented task. If the person does not have the disposition to use the ability, then this could mean two things: (a) either the person is not disposed, in a probability sense, to use or to think to use the ability; or (b) the person is not disposed, in a free will sense, to use the ability that the person recognizes as pertinent to the task. To adjudicate among these possibilities, an extra stage of testing must be pursued. One method suggested here is to interview examinees, asking at first nonleading questions and then, as appropriate, more leading ones. Other possibilities include the use of written responses, and, with ingenuity, the use of a multi-staged multiple-choice test of critical thinking dispositions. Frankly, however, I do not hold out much hope for this latter approach.

\section{References}

Bereiter, C., \& Scardamalia, M. (1985). Cognitive coping strategies and the problem of "inert knowledge." In S.F. Chipman, J.W. Segal, \& R. Glaser (Eds.), Thinking \& learning skills: Current research and open questions (Vol. 2). Hillsdale, NI: Erlbaum.

Blair, J.A. (1992). The generalizability of critical thinking: The evaluation of sources. In S.P, Norris (Ed.), The generalizability of critical thinking (pp. 125-37). New York: Teachers College Press.

Ennis, R.H., \& Weir, E. (1985). The Ennis-Weir Critical Thinking Essay Test. Pacific Grove, CA: Midwest.
Fisher, A. (1991). Testing fairmindedness. Informal Logic, 13(1), 31-35.

Harré, R. (1970). The principles of scientific thinking. Chicago: The University of Chicago Press.

Markman, E.M. (1979). Realizing that you don't understand: Elementary school children's awareness of inconsistencies. Child Development, 50, 643-55.

Norris, S.P. (1990). Effect of eliciting verbal reports of thinking on critical thinking test performance. Joumal of Educational Measurement, 27, 41-58. 
Norris, S.P. (1992). A demonstration of the use of verbal reports of thinking in multiple-choice critical thinking test design. Alberta Journal of Educational Research, 38, 155-176.

Norris, S.P., \& Ennis, R.H. (1989). Evaluating critical thinking. Pacific Grove, CA: Midwest.

Norris, S.P., \& Hollett, A. (1992, July). Two issues concerning the validity of multiple-choice and constructed-response critical thinking tests: Their equivalence and dependence upon critical thinking dispositions. Paper presented at the Fifth International Conference on Thinking, Townsville, Queensland, Australia.

Norris, S.P., \& Ryan, J. (1986). Essay Test of Inductive Reasoning Strategies. St. John's, New- foundland: Memorial University of Newfoundland, Institute for Educational Research and Development.

Perkins, D.N. (1983). Difficulties in everyday reasoning. In W. Maxwell (ed.), Thinking: The Expanding Frontier. Philadelphia: The Franklin Institute Press.

Sheppard, C.N. (1991). The observation competence of grade six science students. Unpublished master's thesis, Memorial University of Newfoundland.

Watson, G. and Glaser, E.M. (1980). Watson-Glaser Critical Thinking Appraisal. Cleveland, $\mathrm{OH}$ : The Psychological Corporation.

\section{Notes}

1 In a conversation with Richard Paul in July, 1992, he indicated that he had given up on the attempted Fairmindedness Subtest. Nevertheless, the illustrations and suggestions in this paper are pertinent to the more general issues of critical thinking testing.

2 Blair (1992) also offers an analysis of the ability/disposition distinction that examines pairs of abilities and dispositions and classifies them as either logically distinct or logically inseparable, and, within the former, as either caus- ally related or causally independent. I believe that Blair would say that the ability and disposition of aluminum to conduct electricity are logically inseparable. I do not, however, agree with his example for this category, namely, the ability and disposition to spell correctly.

STEPHEN P. NORRIS

FACULTY OF EDUCATION

MEMORIAL UNIVERSITY OF NEWFOUNDLAND

ST. JOHN'S, NEWFOUNDLAND AIB $3 X 8$

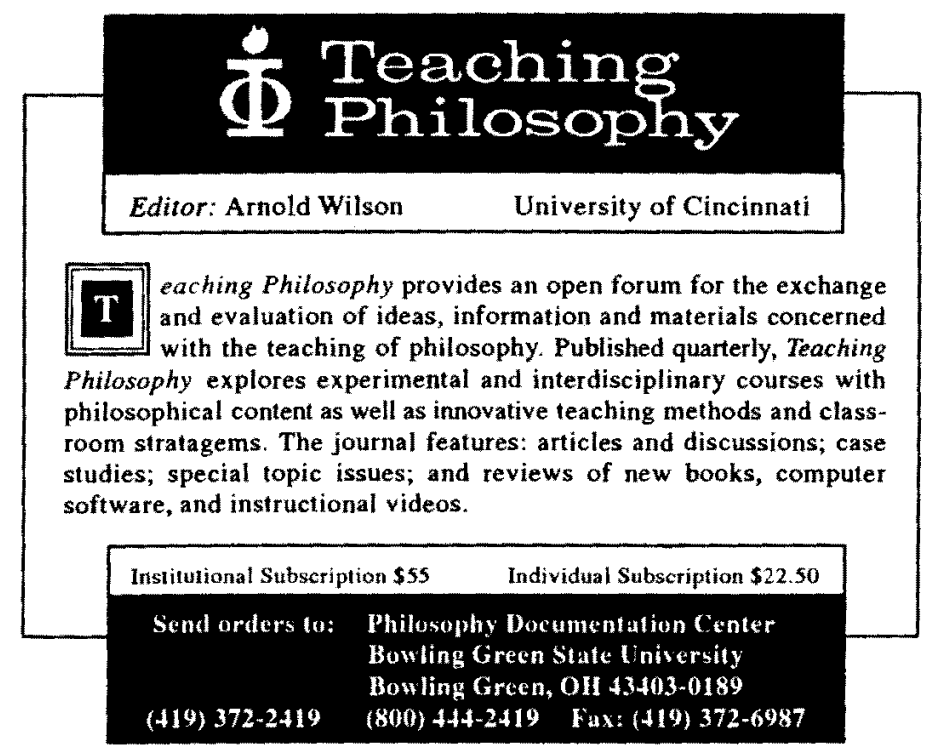

